\title{
Influence of Sterilization Techniques on the In Vitro Bioactivity of Pseudowollastonite
}

\author{
P. N. De $\mathrm{Aza}^{\dagger}$ \\ Instituto de Bioingenieria, Universidad Miguel Hernández, Elche, Alicante, Spain
}

A. H. De Aza

Instituto de Cerámica y Vidrio, CSIC. C/Kelsen, 5. Campus de Cantoblanco, 28049, Madrid, Spain

A. Herrera

Departamento de Cirugía, Universidad de Zaragoza, Zaragoza, Spain

F. A. Lopez-Prats

Departamento de Patología y Cirugía, Universidad Miguel Hernández, Campus de San Juan, Alicante, Spain

P. Pena

Instituto de Cerámica y Vidrio, CSIC. C/Kelsen, 5. Campus de Cantoblanco, 28049, Madrid, Spain

\begin{abstract}
The purpose of this study was to investigate the effect of four sterilization methods (Steam autoclave, Hydrogen peroxide plasma, Ethylene oxide, and Gamma sterilization) on the surface chemistry and in vitro bioactivity of polycrystalline pseudowollastonite (psW). psW samples obtained by solid-state reaction sintering were sterilized and soaked in Kokubo et al.'s proposed simulated body fluid (SBF) up to 30 days. The sterilization procedure was found to result in no significant chemical changes in the surface of the samples. On the other hand, a $\mathrm{Ca} / \mathrm{P}$ layer, of different thickness, identified as hydroxyapatite (HA) like, was developed on all the samples after soaking, although the Ethylene oxide-sterilized samples present a non-homogeneous and $\sim 68 \%$ thinner $\mathrm{HA}$ layer. The psW samples before soaking were analyzed by X-ray diffraction, raman spectroscopy, and scanning electron microscopy (SEM). The interfacial reaction product was examined by SEM fitted with an energy-dispersive X-ray analyzer. Additionally, changes in ionic concentrations at the $\mathrm{psW} / \mathrm{SBF}$ interface were measured.
\end{abstract}

\section{Introduction}

INCE the discovery of bioactive glasses by Hench et al. ${ }^{1}$ in $\$ 1970$, very active research work has been carried out to understand the mechanism and parameters that control bonding at the interface of material-bone. ${ }^{2-5}$ Nowadays, it is generally accepted that the formation of an apatite layer on the surface of bioactive materials is a necessary condition to ensure a direct bone bonding. ${ }^{6-9}$

Bioceramics, including glasses and glass-ceramics, are currently used as implant materials, usually for bone substitution. ${ }^{10-13}$ Before clinical use, all the materials must be sterilized. There are a number of sterilization treatments that can be used, including gamma and laser irradiation, plasma

H. Kim — contributing editor

Manuscript No. 21100. Received October 26, 2005; approved March 31, 2006. This work was supported by CICYT under project no. MAT2003-08331-C2-01-02

†Author to whom correspondence should be addressed. e-mail: piedad@umh.es cleaning, steam sterilization, chemical treatment with ethylene oxide, and some detergents. ${ }^{14-17}$

In spite of a wide application of bioceramics in dentistry and surgery, surprisingly, there are only a few publications related to the influence of the sterilization method used on the chemical properties and bioactivity of bioceramics. For example, steam sterilization has different effects on different calcium phosphates: $\mathrm{CaHPO}_{4} \cdot 2 \mathrm{H}_{2} \mathrm{O}$ (DCPD), calcium-deficient apatite (CDA), and biphasic calcium phosphate (BCP). It has been reported that steam sterilization results in dehydration of DCPD and hydration of the calcium oxide incorporated into the $\mathrm{BCP}$ but no significant changes were found to occur on CDA. ${ }^{18,19}$

The surface of pure stoichiometric hydroxyapatite (HA) was found to remain unchanged after steam sterilization in an autoclave, but sterilization with gamma irradiation resulted in driving off the weakly bonded surface water and distortion of surface phosphate complexes of HA. ${ }^{20}$ Steam sterilization of dental gypsum at $132^{\circ}$ and $121^{\circ} \mathrm{C}$ was found to result in its partial dehydration. ${ }^{21}$

Previous experiments showed that polycrystalline pseudowollastonite $\left(\mathrm{CaSiO}_{3}\right)$, namely psW in short, is bioactive in vitro ${ }^{22-28}$ and in vivo. ${ }^{5,8,9}$ This finding is very significant, as it indicates that psW can be physically and chemically integrated into the structure of living bone tissue, and therefore could be suitable for repair or replacement of living bone. Because the $\mathrm{psW}$ is to be inserted into the body, before clinical use in dentistry or surgery, the psW must be sterilized. So, it appears to be both interesting and important to study the influence of different sterilization treatments on the chemical changes in the surface and in vitro bioactivity of polycrystalline psW after the sterilization.

\section{Materials and Methods}

\section{(1) psW Samples}

The present study was carried out on samples of polycrystalline $\mathrm{psW}, \mathrm{CaSiO}_{3}$. The raw material was previously obtained by solid-state reaction sintering, starting from an appropiate mixture of calcium carbonate, $\mathrm{CaCO}_{3}>99.5 \mathrm{wt} \%$, with an average particle size of $13.8 \mu \mathrm{m}$ and a specific surface area of $0.2 \mathrm{~m}^{2} / \mathrm{g}$ from Merck (Darmstadt, Germany), and high-purity $\mathrm{HCl}$-washed Belgian sand, $\mathrm{SiO}_{2}>99.6$ wt $\%$, with $\mathrm{Fe}_{2} \mathrm{O}_{3}$ content $<30$ ppm and average particle size $>60 \mu \mathrm{m}$. 
As a preliminary step, $\mathrm{SiO}_{2}$ was wet ground in a close chamber laboratory attrition mill using high-purity $3 \mathrm{~mm} \mathrm{Y}_{2} \mathrm{O}_{3}$-stabilized $\mathrm{Zr}_{2} \mathrm{O}$ balls and isopropyl alcohol as suspension media. The powder was then dried and sieved to $<100 \mu \mathrm{m}$. The average particle size, measured by laser diffraction (Model LS 130, Coulter Corp., Miami, FL), of the final $\mathrm{SiO}_{2}$ used was 34.2 $\mu \mathrm{m}$ and the specific surface area, measured by a five-point BET method (Model ASAP 2010, Micromeritics Instrument Corp., Norcross, GA), was $0.4 \mathrm{~m}^{2} / \mathrm{g}$.

Next, the desired proportions of the constituents were weighed out and a $50 \mathrm{wt} \%$ solids aqueous suspension was prepared. To provide maximum chemical stability to the suspension, $0.8 \mathrm{wt} \%$ Dolapix CE 64 (alkali-free polyetectrolite, Zschimmer \& Schwarz, Lanstein, Germany) was added. To obtain a homogeneous and high energetic milled batch, the mixture was wet ground in a laboratory scale annular gap mill ${ }^{29}$ with the same $\mathrm{ZrO}_{2}$ balls mentioned above as grinding media. The average particle size of the final batch was $5.1 \mu \mathrm{m}$. After the milling process, the mixture was dried and burned at $950^{\circ} \mathrm{C}$ for $2 \mathrm{~h}$ to remove the $\mathrm{CO}_{2}$. Then, this powder was sieved to $<30 \mu \mathrm{m}$ and cold isostatically pressed at $200 \mathrm{MPa}$ to produce green compacts.

These compacts were heat treated at $1400^{\circ} \mathrm{C}$ for $6 \mathrm{~h}$ at a heating and cooling rate of $5^{\circ} \mathrm{C} / \mathrm{min}$. The reaction-sintering temperature was selected bearing in mind the information provided by the $\mathrm{SiO}_{2}-\mathrm{CaO}$ phase equilibria diagram evaluated and reported by Eriksson et al. ${ }^{30}$ The obtained material was ground in a tungsten carbide ball mill and then cold isostatically pressed and reheated again. This procedure was repeated once to obtain an X-ray diffraction (XRD) pattern that showed the presence of psW as the only present phase. The average particle size of the obtained psW was $7.0 \mu \mathrm{m}$ and the specific surface area was $1 \mathrm{~m}^{2} / \mathrm{g}$.

The polycrystalline samples of $\mathrm{psW}$ for sterilization and in vitro tests into simulated body fluid (SBF) were then prepared. Samples were uniaxially pressed at $200 \mathrm{MPa}$ to a cylindrical shape in a die and sintered at a heating rate of $5^{\circ} \mathrm{C} / \mathrm{min}$ up to $1400^{\circ} \mathrm{C}$ for $2 \mathrm{~h}$. The final samples were cut from the bars obtained, which were $5 \mathrm{~mm}$ in diameter and $2 \mathrm{~mm}$ in thickness. The bulk density of the obtained psW cylinders, measured by the Archimedes method, was $88 \%$.

\section{(2) Sterilization Methods and Procedure}

(A) Steam Autoclave (EVS 425.2.M): Sealed bags with the samples were sterilized in an autoclave according to the standard procedure DIN 58946 used in medicine. A set of samples were sterilized at $121^{\circ} \mathrm{C}$. Briefly, a single run of the steam sterilization procedure in autoclave includes three stages: temperature increasing up to $121^{\circ} \mathrm{C}$ for $15 \mathrm{~min}$, with a simultaneous pressure increase from 0 to $1.4 \mathrm{mbar}$, sterilization at $121^{\circ} \mathrm{C}$ for $15 \mathrm{~min}$ at a pressure of $1.4 \mathrm{mbar}$, followed by a fast (1-2 min) temperature reduction to $25^{\circ} \mathrm{C}$. Thus, the total time of a single run of the steam sterilization procedure is about $45 \mathrm{~min}$.

(B) Hydrogen Peroxide Plasma (Sterrad): Plasma sterilization treatment was carried out in a large-volume microwave plasma $\left(\mathrm{LMP}^{\mathrm{TM}}\right)$ reactor (SonoSite Inc., Bothell, WA). A set of samples were sterilized by exposing to a $58 \%$ hydrogen peroxide plasma for $15 \mathrm{~min}$. The gas was introduced into the chamber at an operating pressure of 500 MTorr, and plasma was excited with $400 \mathrm{~W}$ of microwave power.

(C) Ethylene Oxide (Steri Vac EOE-M): The units were sterilized by exposing to a $100 \%$ ethylene oxide atmosphere for $156 \mathrm{~min}$ at $55^{\circ} \mathrm{C}$ and a gas concentration of $900 \mathrm{mg} / \mathrm{L}$. After sterilization, the samples are aerated with warm air flow $\left(37^{\circ} \mathrm{C}\right)$ at atmospheric pressure for $330 \mathrm{~min}$ to remove residual ethylene oxide, and stored in indicator bags and sealed.

(D) Gamma Sterilization (Rhodotron TT200): Gamma irradiation sterilization with a ${ }^{60} \mathrm{Co}$ irradiator was performed by Ionmed S.A. (Cuenca, Spain). Randomized samples were packed and sealed in indicator bags and exposed to gamma irradiation in three cycles at doses of $18.71,19.17$, and $18.86 \mathrm{kGy}$, resulting in a dose of $56.34 \mathrm{kGy}$.

\section{(3) In Vitro Test in SBF}

For in vitro studies, in 1990 , Kokubo et al..$^{31}$ proposed the Trisbuffered SBF No. 9 with an ion concentration nearly equal to that of human blood plasma. As, unlike the Tris-buffer ${ }^{32}$ solution alone, SBF contains calcium and phosphorus ions, it can be used to study the in vitro bioactivity of a wider variety of materials. Therefore, in vitro bioactivity tests of all the specimens were carried out in polyethylene bottles by soaking the samples at $37^{\circ} \mathrm{C}$ in $100 \mathrm{~mL}$ of SBF. The immersion period of the pellets in SBF was up to 30 days. This period was chosen based on the results from previous in vitro experiments performed in the $\mathrm{SBF}^{22,23}$ and in human parotid saliva. ${ }^{24,25,33}$

At periodic intervals, the pellets were removed from the fluid and were left to dry in air at room temperature.

\section{(4) Sample Characterization}

Surfaces of the samples were characterized before and after the sterilization treatments. The crystalline structure of the pellets was analyzed by XRD. XRD patterns were recorded on a Bruker-Siemens D5000 automated diffractometer (Bruker AXS GmbH, Karlsruhe, Germany) using $\mathrm{Cu} K \alpha 1,2$ radiation $(1.5418 \AA)$ and a secondary curved graphite monochromator. Data were collected in the Bragg-Brentano $(\theta /$ $2 \theta$ ) vertical geometry (flat reflection mode) between $10^{\circ}$ and $60^{\circ}$

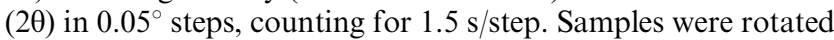
at $30 \mathrm{rpm}$ during acquisition of patterns in order to improve averaging. The diffractometer optic was a system of primary Soller foils between the X-ray tube and the fixed aperture slit. One scattered radiation slit of $1 \mathrm{~mm}$ was placed after the sample, followed by a system of secondary Soller slits and a detector slit of $0.1 \mathrm{~mm}$. The X-ray tube was operated at $40 \mathrm{kV}$ at $30 \mathrm{~mA}$. Raman spectroscopy in the range of $100-1200 \mathrm{~cm}^{-1}$ was also performed.

Additionally, the microstructure of the samples was studied by scanning electron microscopy (SEM) using a Hitachi S$3500 \mathrm{~N}$ (Ibaraki, Japan), fitted with X-ray energy-dispersive spectrometry (EDX). The sample surfaces, before and after exposure to the SBF, and the cross sections, after exposure to the SBF, were examined at $15 \mathrm{keV}$ by SEM. The cross sections were previously polished to a $1 \mu \mathrm{m}$ finish, using a diamond paste, gently cleaned, in an ultrasonic bath, and carbon coated for SEM examination and microanalysis. $\mathrm{Ca}, \mathrm{Si}$, and P EDX elemental maps of the cross sections were collected. The thickness of the precipitated film formed on the sample surfaces was evaluated from the SEM micrographs of the individual cross sections soaked for different time periods into SBF. Additional changes in the ionic concentration of the SBF using inductively couple plasma atomic emission spectroscopy (ICP-AES) were determined.

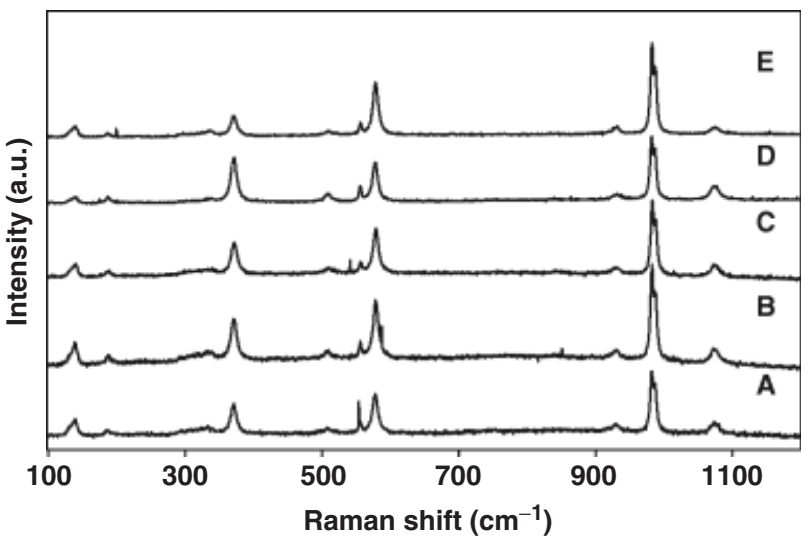

Fig. 1. Raman spectra of the (A) Control sample (non-sterilized), (B) Steam autoclave-, (C) Sterrad-, (D) EtO-, and (E) Gamma-sterilized samples (all the peaks correspond to pseudowollastonite). 


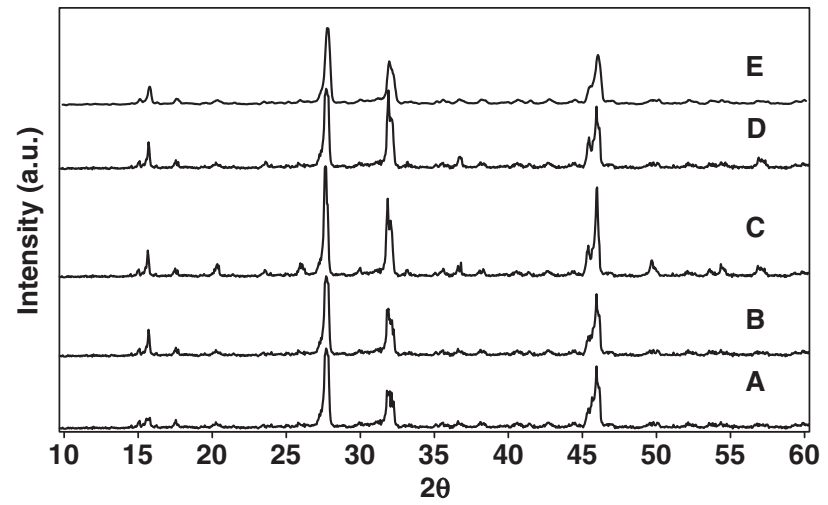

Fig. 2. X-ray diffraction of the (A) Control sample (non-sterilized), (B) Steam autoclave-, (C) Sterrad-, (D) EtO-, and (E) Gamma-sterilized samples (all the peaks correspond to pseudowollastonite).

\section{Results}

The results obtained with Raman spectroscopy on the samples before and after sterilization are shown in Fig. 1. These results demonstrate that no significant chemical changes occur when the samples are sterilized.

XRD analyses of the pellets are shown in Fig. 2. Like the results of Raman measurements, no differences before and after sterilization were observed for all the samples investigated. All the diffracted peaks can be unequivocally identified as psW. Thus, the experimental results using XRD appear to be in perfect agreement with those using Raman spectroscopy.

Figure 3(A) shows the polished surface of the $\mathrm{psW}$ control sample (non-sterilized) where no significant microstructure features can be observed except round and closed pores of average size $\approx 1.8 \mu \mathrm{m}$. Figure 3(B) shows the same psW sample surface after $5 \mathrm{~s}$ of chemical etching with diluted acetic acid. As can be seen, the sample is composed of elongated grains with an average grain size of about $11.3 \mu \mathrm{m}$. Figure $3(\mathrm{C})$ shows the microstructure of the polished and nonetched surface of the Sterrad method-sterilized psW sample as a representative of all the samples studied. The picture is similar to that of the control sample (Fig. 3(A)) presenting a smooth surface with some pores.

SEM micrographs of the psW control and the sterilized samples after 1 and 30 days of soaking are shown in Fig. 4. Steam, Sterrad, and Gamma samples present behavior similar to the psW control. After 1 day of immersion, the material surface was covered by a layer of small globular particles smaller than 3.5 $\mu \mathrm{m}$ in diameter, some of which reached a size of $4.5 \mu \mathrm{m}$ after 7 days of soaking. After 30 days (Fig. 4(B)), the layer covered the entire surface completely and the globular particles reached a size $3-5 \mu \mathrm{m}$ in diameter.

SEM micrographs of Ethylene oxide-sterilized samples, namely EtO in short, after 1 and 30 days of soaking in SBF, are also shown in Fig. 4. The behavior detected was similar to that mentioned previously, although a difference should be pointed out. After a soaking time of 1 day, isolated aggregates of globular particles were detected partially covering the surface. EDX analysis (Fig. 5(A)) showed that these spherical particles
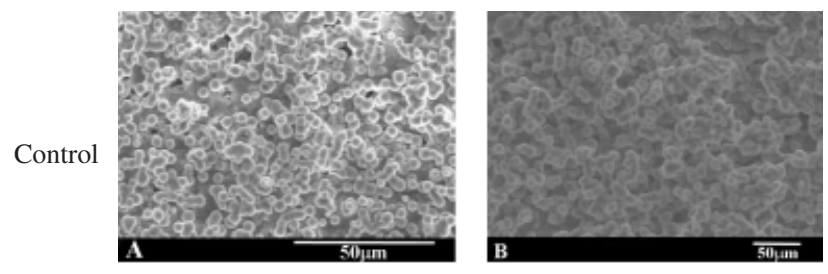

Steam
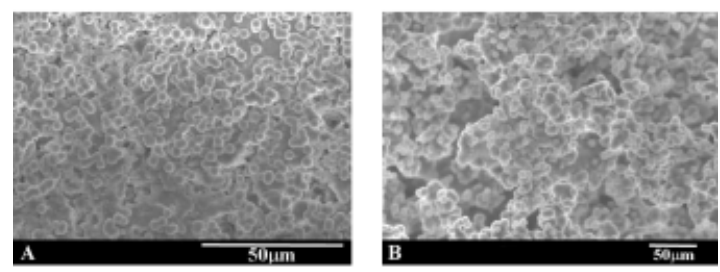

Sterrad
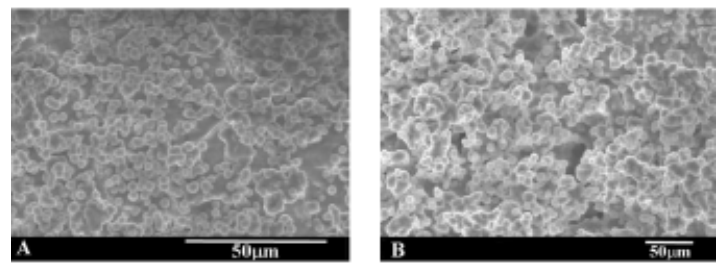

EtO
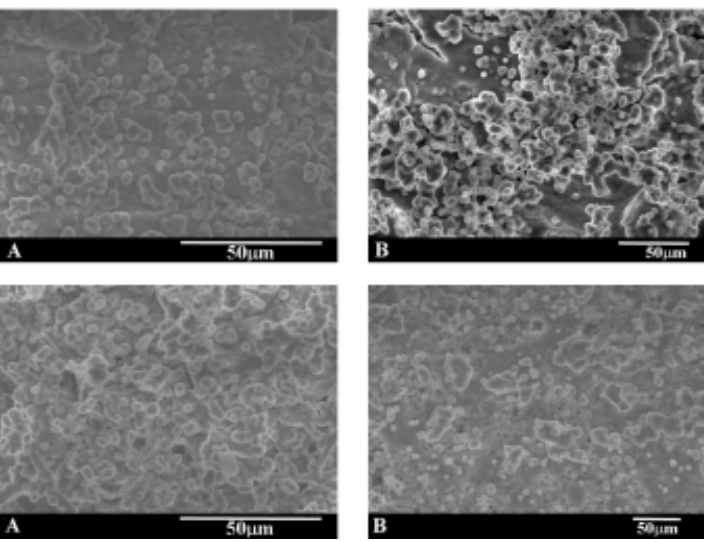

Fig. 4. Scanning electron microscopy images of the sample surfaces. Control sample (non-sterilized) and Steam autoclave-, Sterrad-, EtO-, and Gamma-sterilized samples after immersion into simulated body fluid or (A) 1 day, and (B) 30 days.

are constituted by calcium and phosphorus. In the zones where the aggregates are not present, the background of the sample, EDX confirmed the presence of calcium and silica (Fig. 5(B)). This feature did not change further and the surface was not fully covered by the spherical particles after 30 days of immersion. After 30 days, the globular particles reached a size between 2.5 and $3 \mu \mathrm{m}$ in diameter.

Changes in the elemental ionic concentrations of the SBF after 30 days of immersion are shown in Table I. The composition of the original SBF solution is also reported for comparison. It was found that calcium and silicon ion concentrations in SBF increased slightly over the exposure time, indicating partial
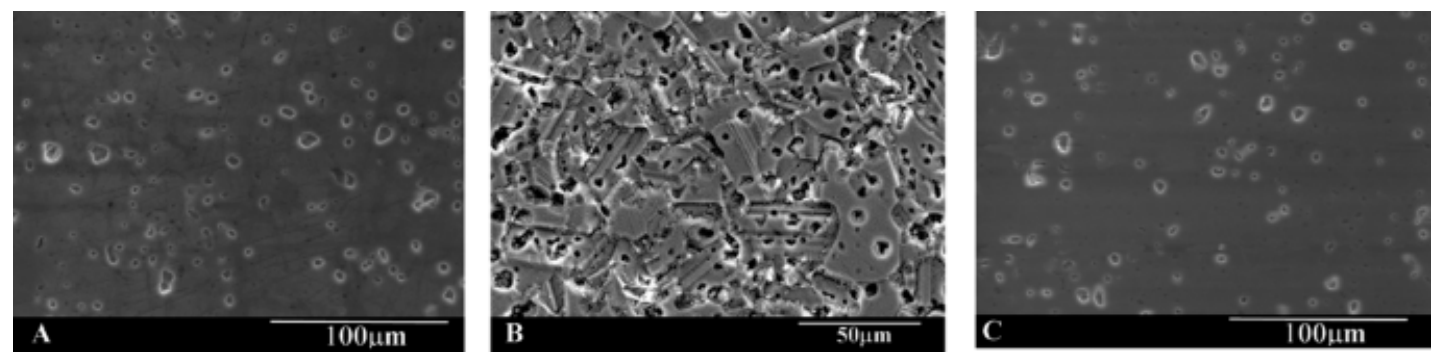

Fig. 3. Scanning electron microscopy micrographs of the pseudowollastonite surface before simulated body fluid immersion. (A) Control sample (nonsterilized), (B) Chemically etched control sample, and (C) Sterrad autoclave-sterilized sample. 

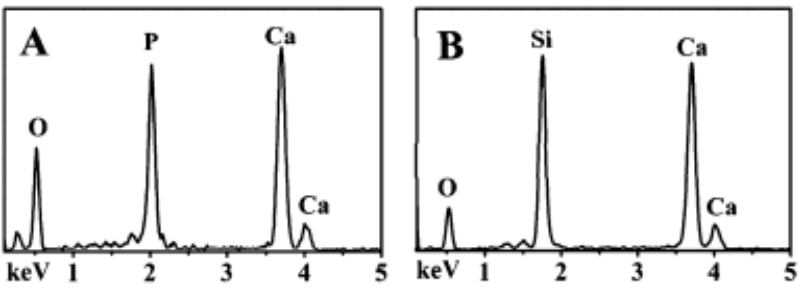

Fig. 5. Energy-dispersive spectrometry of the EtO-sterilized sample after 1 day of immersion in simulated body fluid (A) globular particle, (B) zone where the particles aggregates are not present (sample background).

Table I. Concentration of $\mathrm{Ca}^{2+}, \mathrm{Si}^{4+}$, and $\mathrm{HPO}_{4}^{2-}$, in $\mathrm{SBF}$ Before and After Immersion for 30 Days of the Control Sample (Non-Sterilized) and Steam Autoclave-, Sterrad-, EtO-, and Gamma-Sterilized Samples

\begin{tabular}{lccc}
\hline $\mathrm{mg} / \mathrm{L}$ & $\mathrm{Ca}^{2+}$ & $\mathrm{Si}^{4+}$ & $\mathrm{HPO}_{4}^{2-}$ \\
\hline SBF control solution & 100.15 & - & 96 \\
Control pellet & 105.24 & 9.84 & 65.94 \\
Sterrad & 103.23 & 8.92 & 67.24 \\
Steam autoclave & 106.34 & 9.73 & 75.34 \\
Gamma & 102.57 & 9.94 & 72.94 \\
EtO & 103.47 & 7.94 & 87.32 \\
\hline
\end{tabular}

SBF, simulated body fluid; EtO, ethylene oxide.

dissolution of the psW. On the other hand, phosphorus ion concentration decreased more significantly because of the precipitation of a $\mathrm{Ca}-\mathrm{P}$ phase on the surfaces of the psW samples. Although the formation of the $\mathrm{Ca}-\mathrm{P}$ phase consumed some calcium ions, the calcium ion dissolutions from the psW pellets were more than those consumed. It is remarkable that the minor consumption in phosphorus ions corresponds to the EtO-sterilized samples. This is in agreement with the observed EtO sample surface by SEM after 30 days of immersion (Fig. 4 EtO-D), where the EtO samples do not present the surface fully covered by the globular particles.

Figure 6 shows the relationship between the soaking time and the thickness of the $\mathrm{Ca} / \mathrm{P}$ layer developed on the surface of the ceramic substrate. In the control sample (nonsterilized), a significant thickness of $\mathrm{Ca} / \mathrm{P}$ layer was formed, reaching a total thickness of $\sim 19.3 \mu \mathrm{m}( \pm 0.5 \mu \mathrm{m})$ after 30 days. The formation rate gradually slowed from $\sim 2.5 \mu \mathrm{m} /$ day, after 7 days of soaking, to $0.8 \mu \mathrm{m} /$ day, after prolonged soaking (fourth week of soaking). That is to say, the measurements reveal that the $\mathrm{Ca} / \mathrm{P}$ layer formation kinetic depends directly on the square root of the soaking time. In the Sterrrad-, Stem-, and Gamma-sterilized samples, the morphology of the surface product was the same, although the reaction rate and the thickness of the layer after 30 days were slightly smaller. In Sterradsterilized samples, the total final thickness of the $\mathrm{Ca} / \mathrm{P}$ layer after 30 days of soaking was $19 \mu \mathrm{m}( \pm 1 \mu \mathrm{m}), 18.1 \mu \mathrm{m}( \pm 0.6 \mu \mathrm{m})$ in Stem-sterilized samples, and $17.2 \mu \mathrm{m}( \pm 0.9 \mu \mathrm{m})$ for Gamma method. The main difference was in the EtO-sterilized samples.

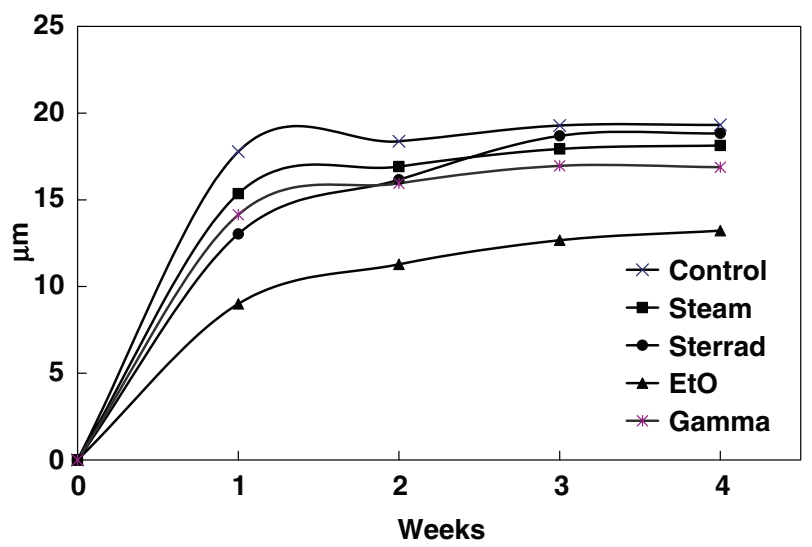

Fig. 6. $\mathrm{Ca} / \mathrm{P}$-layer thickness change as a function of soaking time simulated body fluid: control sample (non-sterilized) and Steam autoclave-, Sterrad-, EtO-, and Gamma-sterilized samples.

Here, it is worth pointing out that the layer detected in the EtOsterilized samples was not of a uniform structure and density throughout the sample. In the areas in which the layer was present, a very low layer formation rate of about $1 \mu \mathrm{m} /$ day, up to $9.1 \mu \mathrm{m}( \pm 0.9 \mu \mathrm{m})$, after 7 days of soaking, was detected. The layer reached a total thickness of $13.2 \mu \mathrm{m}( \pm 0.9 \mu \mathrm{m})$ within these zones.

Figure 7 shows a representative microstructure of the polished cross section of a Sterrad method-sterilized sample after been soaked in SBF for 30 days as a representative of all the samples studied, and its relevant silicon, calcium, and phosphorus EDX maps. This compositional microcharacterization of the interface showed that the reaction zone was composed of two chemically dissimilar layers formed on the material surface. The outer layer indicated a well-textured $\mathrm{Ca} / \mathrm{P}$-rich phase of $19 \mu \mathrm{m}$ $( \pm 1 \mu \mathrm{m})$ average thickness, while the underlayer in direct contact with the psW substrate was rich in silicon. The cracks visible in the picture are an artifact caused by the mandatory drying of the sample for its SEM observation.

\section{Discussion}

The overall results suggest that the mechanism of HA-like phase formation on sterilized psW ceramics in the SBF is in agreement with the mechanisms reported by Hench and Wilson, ${ }^{2}$ Kokuko et al., ${ }^{34}$ Kokuko, ${ }^{35}$ Ohtsuki et al., ${ }^{4}$ and De Aza et al. ${ }^{33}$ This mechanism can be explained in terms of a chemical reaction taking place between the ceramic material and the solution. When the ceramic comes in contact with the SBF, a partial dissolution occurs, producing an ionic exchange of $\mathrm{Ca}^{2+}$ for $2 \mathrm{H}^{+}$ within the material network, leading to the formation of silanol groups on the surface of the ceramic material. Later, there is a partial dissolution of amorphous silica as $\mathrm{SiO}_{3}^{2-}$. This fact enhances the formation of crystallization nuclei for the HA phase, which can be formed from the high concentration of $\mathrm{Ca}^{2+}$ and $\mathrm{HPO}_{4}^{2-}$ present in the media. In summary, a chemical reaction
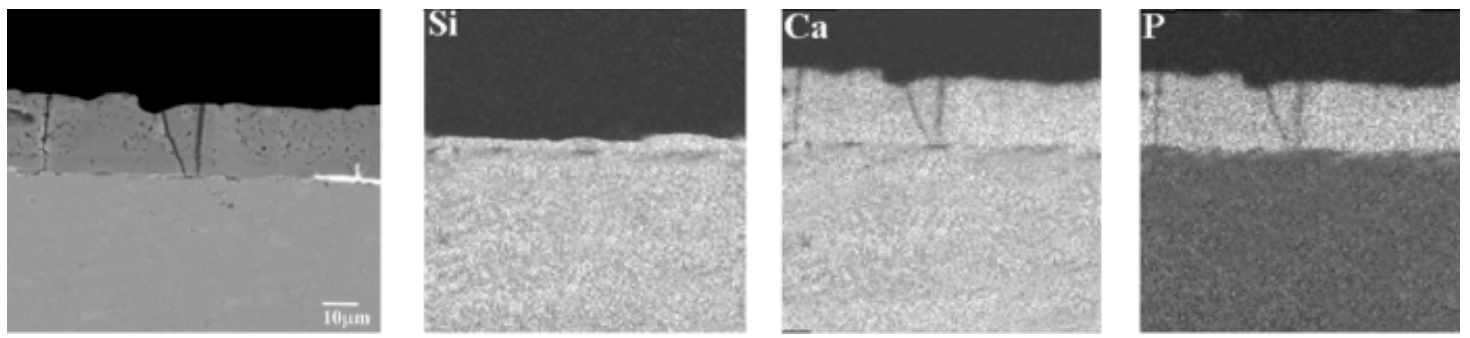

Fig. 7. Scanning electron microscopy image of the cross section of the Sterrad-sterilized sample after 30 days of immersion in simulated body fluid and $\mathrm{Si}, \mathrm{Ca}, \mathrm{P}$ EDX elemental maps. 
takes place between the ceramic and the SBF with the formation of the HA phase.

It is remarkable that the aspect of all sterilized ceramic surfaces after 30 days of soaking is comparable with that shown by other silica-based materials. Generally, the HA-like formation occurs in two stages: a previous formation of globular particles, followed by the apparition of aggregates, which, after 10-15 days of soaking, are indistinguishable. ${ }^{2,4,6,28,33,34}$

The comparison of the results obtained for all sterilized materials points to a disperse nucleation of an HA phase on the EtO sample. Globular aggregates can be detected from the first week of soaking and are heterogeneously distributed over the EtO sample surface. Instead, samples obtained by the other sterilized methods seem to nucleate homogeneously so that the observed layer is formed from a larger number of crystallization nuclei homogeneously distributed as the first week of immersion. The individual growth of these leads to the layer formation.

The reaction rate and the thickness of the $\mathrm{Ca} / \mathrm{P}$ layer formed on the sample surface correspond well with the reported data for various reference materials, such as glass-ceramics $\mathrm{A}-\mathrm{W}$ and a glass-ceramic with the nominal composition of $32.8 \mathrm{wt} \% \mathrm{SiO}_{2}$, $54.5 \mathrm{wt} \% \mathrm{CaO}, 6.0 \mathrm{wt} \% \mathrm{MgO}, 6.1 \mathrm{wt} \% \mathrm{P}_{2} \mathrm{O}_{5}$, and $0.6 \mathrm{wt} \%$ $\mathrm{CaF}_{2}$, as reported by Kokubo ${ }^{35}$ and Liu, ${ }^{36}$ respectively. As mentioned before, the main difference was observed in the EtO-sterilized samples, where the formed layer was not of uniform structure. In the areas in which the layer was detected, a low layer formation rate of about $1 \mu \mathrm{m} /$ day was measured. After 7 days of soaking, the layer reached $9.1 \pm 0.9 \mu \mathrm{m}$ attaining, in these areas, a total thickness of $13.2 \mu \mathrm{m}( \pm 0.9 \mu \mathrm{m})$. This means that in the EtO-sterilized samples, the total $\mathrm{Ca} / \mathrm{P}$ layer formed, after 30 days of immersion, was non-homogeneous throughout the sample and in the areas in which the layer was present, it was about $68 \%$ thinner than in the nonsterilized samples. This is in close agreement with the previously mentioned results obtained by SEM during the surface studies (Fig. 4, EtO-B) where the EtOsterilized samples do not present, after 30 days of immersion, the surface fully covered by the $\mathrm{Ca} / \mathrm{P}$ globular particles. On the other hand, the ICP-AES results of phosphorus ion concentration in $\mathrm{SBF}$ (Table I) show that the minor depletion in $\mathrm{P}$ corresponds to the EtO-sterilized samples. One of the reasons for this difference, in the EtO-sterilized samples, is due to some residual ethylene gas that is possibly present on the surface of the material after sterilization. ${ }^{37-40}$ As it was reported elsewhere, ${ }^{37-40}$ there are problems with the toxicity and carcinogenicity of the residual ethylene gas in materials. So, the residual ethylene gas should also affect the nucleation and crystal growth of HA.

It is expected that the process of the new $\mathrm{Ca}-\mathrm{P} /$ layer formation at the surface of the sterilized ceramics would continue for as long as the ion exchange mechanism between the materials and the SBF takes place. It is expected that the process will come to an end when the supply of $\mathrm{P}$ ions from the SBF terminates, or when the diffusion of the ions across the interface is stopped due to the thickness of the new $\mathrm{Ca}-\mathrm{P} /$ layer reaching a critical value.

\section{Conclusions}

The influence of four sterilization methods (Steam autoclave, Hydrogen peroxide plasma, Ethylene oxide, and Gamma sterilization) on the surface chemistry and the in vitro bioactivity of polycrystalline psW ceramics was investigated.

Because Raman spectroscopy and XRD results appeared basically similar, it has been shown that there was no significant modification of the psW crystalline structure on the surface of the samples by the four sterilization methods used.

SEM observation, after the SBF soaking, showed essentially identical surface morphology regardless of the sterilization by Ethylene oxide, where the HA layer does not fully cover the surface of the samples after 30 days of immersion. One of the reasons for this difference is due to some residual ethylene gas that is possibly present on the surface of the EtO-sterilized sam- ples after sterilization. This residual ethylene gas should affect the nucleation and crystal growth of HA.

The sterilization procedures used lead to an adequate bioactivity, with the formation of an HA-like layer on the surface of all the samples, although the EtO-sterilized samples present an $\sim 68 \%$ thinner and non-homogeneous HA-like deposition throughout the samples.

\section{Acknowledgments}

The authors wish to thank Dr. Luna from Ionmed SA (Cuenca, Spain) for the Gamma sterilization. Thanks are also due to Dr. J. A. Fernandez Pradas for providing help with Raman spectroscopy experiments. The authors also wish to acknowledge the contribution of Prof. Salvador De Aza in offering valuable suggestions and stimulating discussion during the course of this work. The authors are deeply indebted to him.

\section{References}

${ }^{1}$ L. L. Hench, R. J. Splinter, T. K. Greenle, and W. C. Allen, "Bonding Mechanisms at the Interface of Ceramic Prosthetic Materials," J. Biomed. Mater. Res. Symp., 2, 117 (1971).

${ }^{2}$ L. L. Hench and J. W. Wilson, "Surface-Active Biomaterials," Science, 226, 630-6 (1984)

${ }^{3}$ P. N. De Aza, A. H. De Aza, and S. De Aza, "Crystalline Bioceramic Materials," Bol. Soc. Esp. Ceram. Vidrio, 44 [3] 135-45 (2005).

${ }^{4}$ C. Ohtsuki, T. Kokubo, and T. Yamamuro, "Mechanism of Apatite Formation on $\mathrm{CaO}-\mathrm{SiO}_{2}-\mathrm{P}_{2} \mathrm{O}_{5}$ Glasses in a Simulated Body Fluid," J. Non-Cryst. Solids, 143, 84-92 (1992).

${ }^{5}$ P. N. De Aza, Z. B. Luklinska, C. Santos, F. Guitian, and S. De Aza, "Mechanism of Bone-Like Formation on a Bioactive Implant In Vivo," Biomaterials, 24, 1437-45 (2003)

${ }^{6} \mathrm{~K}$. Ohura, T. Nakamura, T. Yamamuro, T. Kokubo, T. Ebisawa, Y. Kotoura, and M. Oka, "Bone-Bonding Ability of $\mathrm{P}_{2} \mathrm{O}_{5}$-Free $\mathrm{CaO} \cdot \mathrm{SiO}_{2}$ Glasses," J. Biomed. Mater. Res., 25, 357-65 (1991).

${ }^{7}$ L. Devesa, A. Pazo, C. Santos, A. Martinez, F. Guitian, and J. S. Moya, "SiO Based Glass/Bone Interfacial Reactions," Acta Mater., 46 [7] 2559-63 (1998).

${ }^{8}$ P. N. De Aza, Z. B. Luklinska, A. Martinez, M. R. Anseau, F. Guitian, and S De Aza, "Morphological and Structural Study of Pseudowollastonite Implants in Bone," J. Microsc. Oxford, 197 [1] 60-7 (2000).

${ }^{9}$ P. N. De Aza, Z. B. Luklinska, M. R. Anseau, F. Guitian, and S. De Aza, "Transmission Electron Microscopy of the Interface Between Pseudowollastonite Implants and Bone "In Vivo"," J. Microsc. Oxford, 201 [1] 33-43 (2001).

${ }^{10}$ T. Kokubo, S. Ito, S. Sakka, and T. Yamamuro, "Formation of a HighStrength Bioactive Glass-Ceramic in the System $\mathrm{MgO}-\mathrm{CaO}-\mathrm{SiO}_{2}-\mathrm{P}_{2} \mathrm{O}_{5}$," J. Mater. Sci., 21, 536-40 (1986).

${ }^{11}$ U. Gross, R. Kinne, H. J. Schmitz, and V. Strunz, "The Response of Bone to Surface Active Glass/Glass-Ceramics," CRC. Crit. Rev. Biocompat., 4 [2] 155-79 (1988).

${ }^{12}$ G. G. Vargas, N J. Menendez, O L. Lopez, P. N. De Aza, and S. De Aza, "Cementos Odontológicos a Base de Poli (Acido Acrilico) y Wollastonita," Bol. Soc. Esp. Ceram. Vidrio, 44 [2] 89-94 (2005).

${ }^{13}$ P. N. De Aza, J. M. Fernandez-Pradas, and P. Serra, "In Vitro Bioactivity of Laser Ablation Pseudowollastonite Coating,” Biomaterials, 25, 1983-90 (2004).

${ }^{14} \mathrm{M}$. Goldman, R. Gronsky, and L. Pruitt, "The Influence of Sterilization Technique and Ageing on the Structure and Morphology of Medical-Grade U1trahigh Molecular Weight Polyethylene," J. Mater. Sci. Mater. Med., 9, 207-12 (1998)

${ }^{15}$ R. S. Benson, "Use of Radiation in Biomaterials Science," Nucl. Instrum. Methods Phys. Res., 191B, 752-7 (2002).

${ }^{16}$ E. M. Noah, J. Chen, X. Jiao, I. Heschel, and N. Pallua, "Impact of Sterilization on the Porous Design and Cell Behaviour in Collagen Sponges Prepared for Tissue Engineering," Biomaterials, 23, 2855-61 (2002).

${ }^{17}$ M. Takechi, Y. Miyamoto, Y. Momota, T. Yuasa, S. Tatehara, M. Nagayama, and K. Ishikawa, "Effects of Various Sterilization Methods on the Setting and Mechanical Properties of Apatite Cement," J. Biomed. Mater. Res., 69B, 5863 (2004).

${ }^{18}$ S. V. Dorozhkin, M. Schmitt, J. M. Bouler, and G. Daculsi, "Chemical Transformation of Some Biologically Relevant Calcium Phosphates in Aqueous Media During a Steam Sterilization," J. Mater. Sci. Mater. Med., 11, 779-86 (2000).

${ }^{19}$ J. Suwanprateeb, K. E. Tanner, S. Turner, and W. Bonfield, "Influence of Sterilization by Gamma Irradiation and of Thermal Annealing on Creep of Hydroxyapatite-Reinforced Polyethylene Composites," J. Biomed. Mater. Res., 39 [1] $16-22$ (1998).

${ }^{20}$ J. M. Bouler, M. Trecant, J. Delecrin, J. Royer, N. Passuti, and G. Daculsi, "Macroporous Biphasic Calcium Phosphate Ceramics: Influence of Five Synthesis Parameters on Compressive Strength," J. Biomed. Mater. Res., 32 [4] 603-9 (1996).

${ }^{21}$ M. P. Whyte and P. J. Brockhurst, "The Effect of Steam Sterilization on the Properties of Set Dental Gypsum Models," Aust. Dental J., 41 [2] 128-33 (1996).

${ }^{22}$ P. N. De Aza, F. Guitian, and S. De Aza, "Bioactivity of Wollastonite Ceramics: In Vitro Evaluation,” Scr. Metall. Mater., 31, 1001-5 (1994).

${ }^{23}$ P. N. De Aza, F. Guitian, and S. De Aza, "Polycrystalline Wollastonite Ceramics. Biomaterials Free of $\mathrm{P}_{2} \mathrm{O}_{5}$ "; pp. 19-27 in Advances in Science and Technology, Vol. 12. Materials in Clinical Application, Edited by P. Vincenzini. Techna Srl., Faenza, Italy 1995. 
${ }^{24}$ P. N. De Aza, Z. B. Luklinska, M. R. Anseau, F. Guitian, and S. De Aza, "Bioactivity of Pseudowollastonite in Human Saliva," J. Dent., 27, 107-13 (1999)

${ }^{25}$ P. N. De Aza, Z. B. Luklinska, and M. R. Anseau, "Bioactivity of Diopside Ceramic in Human Parotid Saliva," J. Biomed. Mater. Res., 73B [1] 54-60 (2005).

${ }^{26}$ D. Dufrane, C. Delloye, I. Mc.Kay, P. N. De Aza, S. De Aza, Y. J. Shneider, and M. Anseau, "Indirect Citotoxicity Evaluation of Pseudowollastonite," $\mathrm{J}$. Mater. Sci. Mater. Med., 14 [1] 33-8 (2003).

${ }^{27}$ C. Sarmento, Z. B. Luklinska, L. Brown, M. Anseau, S. De Aza, P. N. De Aza, S. F. Hughes, and I. McKay, "The In Vitro Behaviour of Osteoblastic Cell Cultured in the Presence of Pseudowollastonite Ceramic," J. Biomed. Mater. Res., 69A [2] 351-8 (2004)

${ }^{28}$ M. I. Alemany, P. Velasquez, M. A. de la Casa-Lillo, and P. N. De Aza, "Effect of Materials' Processing Methods on the "In Vitro" Bioactivity of Wollastonite Glass-Ceramic Materials," J. Non-Cryst. Solids, 351, 1716-2 (2005).

${ }^{29}$ W. Cremer, "Defined Grinding in a Grinding Chamber Former as an Annular Gap," Interceramic, 5, 59-61 (1989).

${ }^{30}$ G. Eriksson, P. Wu, M. Blander, and A. D. Pelton, "Critical Evaluation and Optimisation of the Thermodynamic Properties and Phase Diagrams of the MnO$\mathrm{SiO}_{2}$ and $\mathrm{CaO}-\mathrm{SiO}_{2}$ Systems," Can. Metall. Q., 33, 13-21 (1994).

${ }^{31}$ T. Kokubo, H. Kushitani, S. Sakka, T. Kitsugi, and T. Yamamuro, "Solutions Able to Reproduce In Vivo Surface-Structure Changes in Bioactive GlassCeramics A-W,' J. Biomed. Mater. Res., 24, 721-34 (1990).
${ }^{32}$ C. G. Pantano, A. E. Clark, and L. L. Hench, "Multilayer Corrosion Films on Bioglass Surfaces," J. Am. Ceram. Soc., 57, 412-3 (1974).

${ }^{33}$ P. N. De Aza, Z. B. Luklinska, M. Anseau, M. Hector, F. Guitian, and S. De Aza, "Reactivity of Wollastonite-Tricalcium Phosphate Bioeutectic Ceramic in Human Parotid Saliva," Biomaterials, 21 [17] 1735 (2000).

${ }^{34}$ T. Kokubo, T. Hayashi, S. Sakka, T. Kitsugi, and T. Yamamuro, "Bonding Between Bioactive Glasses, Glass-Ceramics or Ceramics in Simulated Body Fluid," Yogyo Kyokai Shi, 95 [8] 785-91 (1987).

${ }^{35}$ T. Kokubo, "Surface Chemistry of Bioactive Glass-Ceramics," J. Non-Cryst. Solids, 120, 138-51 (1990).

${ }^{36}$ D.-M. Liu, "Bioactive Glass-Ceramic: Formation, Characterization and Bioactivity," Mater. Chem. Phys., 36, 294-303 (1994).

${ }^{37}$ E. J. Harper, M. Braden, W. Bonfield, E. Dingeldein, and H. Wahlig, "Influence of Sterilization Upon a Range of Properties of Experimental Bone Cements," J. Mater. Sci. Mater. Med., 8, 849-53 (1997).

${ }^{38}$ G. Lewis and S. Mladsi, "Effect of Sterilization Method on Properties of Palacos Acrylic Bone Cement," Biomaterials, 19, 117-24 (1998).

${ }^{39}$ C. Zahraoui and P. Sharrock, "Influence of Sterilization on Injectable Bone Biomaterials," Bone, 25, 63S-5 (1999).

${ }^{40}$ V. D. Sainz, N. D. Rodriquez, E. G. Fuentes, S. W. Guerra, A. Arcis, E. Peon, A. J. Diaz, and S. D. Zaldivar, "Radiation Sterilization of Abifunctional Cement Formulation of Hydroxilapatite-Plasterpolymers," Ann. N.Y. Acad. Sci., 18, 64-70 (1999). 